\title{
Normocapnic anaesthesia for intraocular surgery
}

\author{
A. P. ADAMS, A. FREEDMAN, AND J. D. HENVILLE \\ From the Nuffield Department of Anaesthetics, Radcliffe Infirmary, Oxford, and the Oxford Eye Hospital
}

SUMMARY Measurement of intraocular pressure (IOP) by applanation tonometry in 23 patients undergoing lens extraction showed that a normocapnic general anaesthetic technique with controlled ventilation of the lungs (IPPV) reliably reduced the IOP by $50 \%$ for the duration of the operative period. This was not associated with large falls in systemic arterial pressure which are often a feature of spontaneously breathing halothane anaesthesia for eye surgery. Normocapnia and IPPV were easy to achieve by use of the single-limb coaxial Bain anaesthetic breathing circuit in conjunction with an electrically driven, small, and inexpensive ventilator while the anaesthetic mixture of $33 \%$ oxygen and $0.5 \%$ halothane in nitrous oxide was delivered at a rate of $70 \mathrm{ml} / \mathrm{kg}$ body weight per minute.

It is only in recent years that general anaesthesia has been used for the majority of patients undergoing eye surgery. Local anaesthesia continues in use, especially since most patients presenting for intraocular surgery are elderly and often suffer from cardiovascular, respiratory, or metabolic diseases. In addition coughing, straining, or vomiting resulting from the administration of a general anaesthetic can produce large rises in intraocular pressure (IOP). However, the supremacy of local anaesthesia has now been abolished by improvements in general anaesthesia resulting from a wider choice of drugs and techniques, so that the surgeon enjoys a relaxed atmosphere and the apprehension of the patient is eliminated.

Most general anaesthetic methods produce a fall in IOP (Magora and Collins, 1961), but this ideal condition is most easily produced by a technique of controlled ventilation using muscle relaxants. This is because of the significant effect which a low arterial carbon dioxide tension produced in this way has on IOP(Adams and Barnett, 1966; Samuel and Beaugié, 1974). This technique is also particularly suitable for elderly patients with their reduced respiratory reserve and tendency to respiratory depression. However, the resumption of adequate spontaneous respiration after antagonism of residual neuromuscular blockade may be delayed, thereby slowing turnround of patients on a busy operating list.

Address for reprints: Dr A. P. Adams, Nuffield Department of Anaesthetics, Radcliffe Infirmary, Oxford
Many anaesthetists have favoured a technique of spontaneous respiration using nitrous oxide, oxygen, and halothane, because recovery from anaesthesia is prompt (Kaufman, 1967; Adams and Fordham, 1973). However, the disadvantage of this technique is that halothane in inspired concentrations of 1.5 to $2 \%$ needs to be given to be sure that the patient does not react during the operation. These concentrations may eventually lead to tachypnoea and shallow breathing, resulting in respiratory acidosis. The effect of a rise in arterial carbon dioxide tension $\left(\mathrm{PaCO}_{2}\right)$ on IOP is offset to some extent by the effect of halothane (Al-Abrak and Samuel, 1974). However, eventually these doses of halothane may cause profound hypotension in elderly patients. The hypotension is most marked in patients who have essential hypertension and who are not receiving medical treatment (Prys-Roberts et al., 1971). This problem hardly ever arose when the Graefe knife was in vogue, as the time of operation was so short. However, most intraocular surgery now takes longer because of the use of the operating microscope and more elaborate suturing techniques. These advances have highlighted the deficiencies of the spontaneous breathing anaesthetic technique.

This paper considers the effects on intraocular pressure of a simple standardised technique by means of muscle relaxants and controlled ventilation at normocapnia with the recently-introduced Bain coaxial circuit (Bain and Spoerel, 1972; Henville and Adams, 1976a). This circuit is a coaxial form of the Mapleson $D / E$ type breathing circuit, which 
Fig. 1 Circuit diagram of coaxial anaesthetic breathing circuit connected to Cape Minor lung ventillator

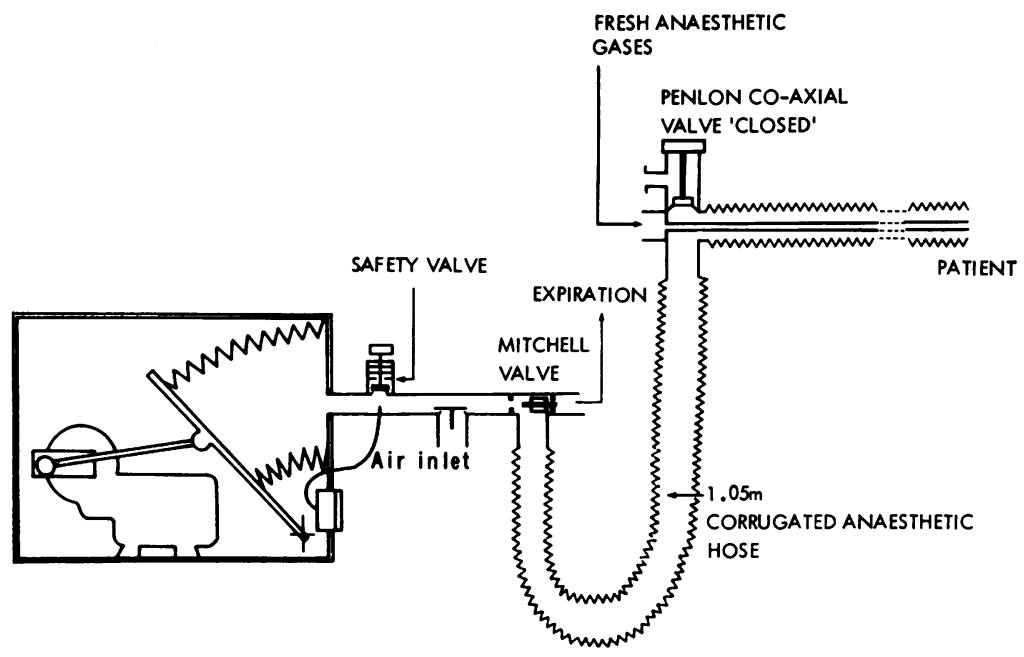

through controlled rebreathing maintains the $\mathrm{PCO}_{2}$ at a level determined by the flow of fresh gas into the circuit (Fig. 1).

\section{Patients and methods}

\section{PATIENTS}

Twenty-three patients with cataracts were admitted for lens extraction under general anaesthesia. There were 12 males and 11 females. Their mean age was 72 years (range 37 to 88 years) and mean weight $65.3 \mathrm{~kg}$ (range 39 to $101.4 \mathrm{~kg}$ ). The anaesthetist saw all the patients preoperatively and assessed their fitness. No attempt was made to select patients other than to exclude those who either were untreated hypertensives whose diastolic pressure was greater than $110 \mathrm{mmHg}$ or were in gross congestive cardiac failure. Several patients were taking medication in the form of digoxin, antihypertensive drugs, diuretics, potassium supplements, oral hypoglycaemic drugs, mild analgesics and night sedatives, or tranquillisers.

MEASUREMENTS OF IOP

When the patients arrived in the anaesthetic room the cornea of both eyes was anaesthetised by the application of 1 to 2 drops of $0.5 \%$ proxymetacaine (Ophthaine) solution. Fluorescein was then applied from dye-impregnated paper strips, and the IOP was measured by a Perkins hand-held applanation tonometer (Perkins, 1965).

All tonometric measurements were performed by the same person (A.F.) Further IOP measurements were made in both eyes 10 minutes after the initial readings had been obtained, which was after full general anaesthesia had been established with controlled ventilation of the lungs. Tonometry was also performed on the non-operated eye both at the conclusion of surgery while the general anaesthetic was maintained and immediately after spontaneous breathing had been re-established following withdrawal of the anaesthetic gases and the antagonism of residual neuromuscular block. Difficulties in obtaining a clear end-point with the tonometer at this time due to the uptake of fluorescein by the cornea occurred in 3 patients. These patients have been excluded from the study.

\section{ANAESTHESIA}

All patients were premedicated with $0.6 \mathrm{mg}$ atropine given intramuscularly about 1 hour before surgery. This is not believed to have any effect on IOP. Induction of anaesthesia is likely to be accompanied by a rise of IOP because of the administration of suxamethonium followed by tracheal intubation (Taylor et al., 1968; Pandey et al., 1972). General anaesthesia was induced with intravenous thiopentone 4 to $5 \mathrm{mg} / \mathrm{kg}$ followed immediately by suxamethonium $1.5 \mathrm{mg} / \mathrm{kg}$; this large dose of suxamethonium helps to permit easy tracheal intubation under profound paralysis with no reaction from the patient and minimises the rise in IOP.

The extraocular muscles have been shown to exhibit a biphasic response to suxamethonium on account of their possession of two types of muscle fibre: tonic, multi-inverted fibres which respond only to tetanic stimuli with a slow contraction, and phasic, singly innervated fibres which respond with a twitch to a single stimulus. A dose of suxamethonium which relaxes skeletal muscle may produce a tonic contracture of the extraocular muscles, 
squeezing the eyeball and producing a transient rise in IOP (Gibb, 1974; Wislicki, 1976). If, however, a sufficiently large dose of suxamethonium is given, relaxation of both types of muscle fibre is produced (Joshi and Bruce, 1975).

Laryngoscopy was performed after inflation of the lungs with oxygen. The vocal cords and trachea were sprayed with 1 to $2 \mathrm{ml} 4 \%$ lignocaine, and the trachea was intubated with size 8 to 9 Oxford pattern non-kinking cuffed endotracheal tube (Duckworth, 1962).

\section{VENTILATION}

Ventilation was controlled initially by hand, a mixture of $33 \%$ oxygen, and $0.5 \%$ halothane in nitrous oxide being delivered from a Bain anaesthetic breathing circuit. The purpose of the halothane was to ensure unconsciousness during the operation while permitting an adequate concentration of inspired oxygen in this elderly group of patients, and also to reduce the IOP. The fresh-gas flow from the anaesthetic machine was adjusted to give a total flow $\left(\dot{V}_{\ell}\right)$ as close to $70 \mathrm{ml} / \mathrm{kg}$ per minute as possible so as to obtain normocapnia during the operation (Bain and Spoerel, 1973; Henville and Adams, 1976b). The anaeshetic machine used was a British Oxygen Company Boyle's machine model E; the etchings on the Rotameter tubes of this old machine permitted a more exact setting of fresh gas flows than is possible with the new 'long-range' double-tapered tubes provided on more modern machines.

Gallamine triethiodide (Flaxedil) in a dose of $2 \mathrm{mg} / \mathrm{kg}$, but not exceeding $120 \mathrm{mg}$ in a single dose, was then given intravenously to permit synchronisation with an automatic lung ventilator which provided intermittent positive pressure ventilation (IPPV) of the lungs throughout the operation. It must be emphasised that this dose is insufficient to permit tracheal intubation without the patient's reacting. Gallamine was chosen because of its short duration of action and lack of serious side effects. The tachycardia induced by the drug caused no problems; in particular bleeding was not exaggerated.

Electrically powered anaesthetic ventilators were used for convenience, as medical gas supplies from pipelines were unavailable. Two types of machine were used. (a) A British Oxygen Company Mark 4 Beaver ventilator was used on 21 patients. This machine is a pressure preset machine (Mushin et al., 1969); the 'over-pressure' relief valve had been modified in the anaesthetic workshop to allow slightly higher peak inflating pressures to be used than the $30 \mathrm{cmH}_{2} \mathrm{O}$ originally permitted. (b) A Cape Minor Ventilator, which is a volume-preset machine (Collis, 1967), was used on the remaining 2 patients.
Both these ventilators delivered room air into the Bain anaesthetic system. The interposition of a $1.05-\mathrm{m}$ length of standard anaesthetic corrugated breathing hose ( $22 \mathrm{~m}$ diameter) between the ventilator and the beginning of the outer limb of the Bain circuit ensured that the air did not enter the patients' lungs (Adams, 1977a).

In order to keep mean intrathoracic pressure low during such IPPV and to maintain optimal ventilation of the lungs during anaesthesia the tidal volume was adjusted to about $10 \mathrm{ml} / \mathrm{kg}$ with a slow respiratory frequency. However, the Cape Minor machine had a slight disadvantage because its frequency could not be reduced from the fixed rate of 16 cycles/minute. Expired minute volumes and tidal volumes were checked by inserting an electronic Wright's respirometer (Conway et al., 1974) (BOCMedishield Ltd.) between the catheter mount and the Bain circuit. Although the additional dead-space introduced was only about $22 \mathrm{ml}$, the instrument was removed when the desired ventilation had been achieved and before the operation began. A repeat check of the ventilation was performed at the end of surgery.

Ventilation was continued throughout the operation, which lasted 30 to 40 minutes on average. It was not found necessary to give any further muscle relaxant. Half-way through the operation $10 \mathrm{mg}$ of metoclopramide was given intramuscularly as a prophylactic against sickness in the postoperative period.

In the concluding phase of the operation arterial blood was sampled from the radial artery. The 2-ml syringes containing blood samples were transported in iced water to the blood-gas laboratory where analysis was performed within 45 minutes with Radiometer $\mathrm{PO}_{2}, \mathrm{PCO}_{2}$, and $\mathrm{pH}$ electrodes. Standard corrections were applied to these results for storage time (Kelman and Nunn, 1966). At the end of the operation IOP was measured in the non-operated eye. Residual neuromuscular block was then reversed with $0.6 \mathrm{mg}$ atropine (or $1.2 \mathrm{mg}$ if the tachycardia from the gallamine had worn off) and $2.5 \mathrm{mg}$ neostigmine, the secretions in the pharynx were aspirated, and the endotracheal tube was removed. No problems due to profuse salivation or vomiting followed neostigmine administration. Oxygen was administered through an anaesthetic face mask, care being taken not to press on the eyes, and spontaneous breathing was resumed well within 5 minutes. At this point the IOP was again determined. The patient was then turned on to one side and given oxygen-enriched air to breathe from a plastic disposable MC oxygen mask for a minimum period of 10 minutes, and on regaining complete consciousness was returned to the ward. 
Fig. 2 Intraocular pressure determined by applanation tonometry at various stages of anaesthesia and surgery

$\mathrm{O}=$ Operated eye.

- Non-operated eye.

$-=$ Mean IOP

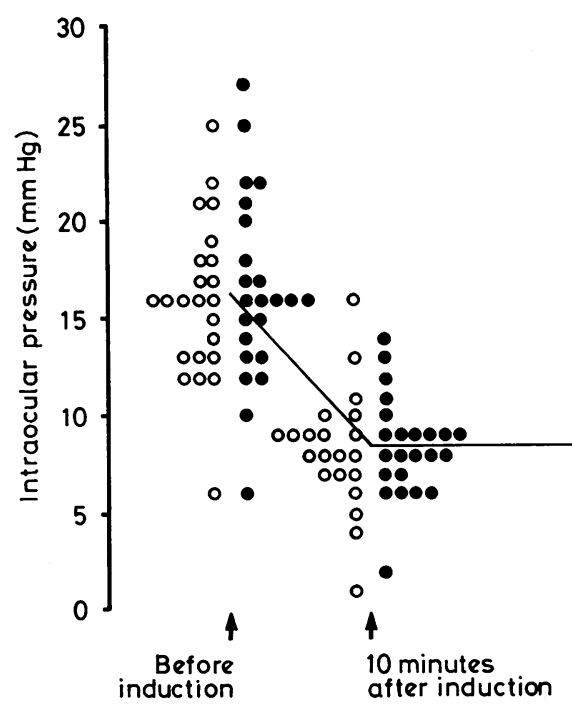

(A)
(B)

\section{Results}

\section{ANAESTHESIA}

The mean total fresh-gas flow $\left(\dot{V}_{f}\right)$ set on the anaesthetic flowmeters was $4 \cdot 7$ litres/minute; this corresponded well with the calculated desired requirements for normocapnia of 4.6 litres/minute.

The mean expired minute volume $\left(\dot{\mathrm{V}}_{\mathrm{E}}\right)$ was 9.4 litres/minute, that is, $144 \mathrm{ml} / \mathrm{kg}$ per minute, at a mean frequency of ventilation of 13 cycles/minute giving a mean tidal volume of $11 \mathrm{ml} / \mathrm{kg}$.

\section{INTRAOCULAR PRESSURE}

The mean intraocular pressure (IOP) measured in the anaesthetic room immediately before the establishment of general anaesthesia was $16.0 \mathrm{mmHg}$ in the eye to be operated upon and $16.5 \mathrm{mmHg}$ in the other eye; this difference was not significant $(t=0.437)$. Measurements made 10 minutes after the induction of anaesthesia with the patient in the operating theatre and the surgeon ready to start the operation showed equally marked falls of almost $50 \%$ in the IOP in both eyes (Fig. 2 and Table 1). There was no statistical difference between the mean pressure in either eye.

The duration of surgery was 30 to 40 minutes. The mean IOP at the end of surgery was $7.9 \mathrm{mmHg}$ which was not statistically significant from the pressure just before starting the operation. However, the IOP rose to $12 \cdot 1 \mathrm{mmHg}$ when the anaesthetic was discontinued and spontaneous breathing became re-established. This rise was statistically significant $(\mathbf{P}<0.001)$ when compared with the IOP at the end of operation. It is likely that the IOP continued to rise, because this final measurement was still significantly less than that obtained preoperatively $(\mathbf{P}<0.001)$.

\section{ARTERIAL PRESSURE}

Systolic arterial pressure fell from a mean preoperative value of $151 \mathrm{mmHg}$ in the anaesthetic room to a mean of $113 \mathrm{mmHg} 10$ minutes after the induction of anaesthesia. The pressure remained

Table 1 IOP in 23 patients before, during, and at the end of general anaesthesia. There is no significant difference between the IOP results given for the operated and the non-operated eye. The statistical differences for $I O P$ between the groups gave by Student's t $P<0.001$, except that there was no significant difference between groups $\mathrm{B}$ and $\mathrm{C}$. Mean $\mathrm{PaCO}_{2} 42.0 \mathrm{mmHg}$ ( $\mathrm{SE}$ mean 0.98), mean $\mathrm{PaO}_{2} 127.6 \mathrm{mmHg}$ ( $S E$ mean 4.4)

\begin{tabular}{|c|c|c|c|}
\hline & & \multicolumn{2}{|c|}{$I O P(S E$ mean $)(m m H g)$} \\
\hline & & $\begin{array}{l}\text { Non-operated } \\
\text { eye }\end{array}$ & $\begin{array}{l}\text { Operated } \\
\text { eye }\end{array}$ \\
\hline$A$ & $\begin{array}{l}\text { Before induction of general } \\
\text { anaesthesia (systolic arterial } \\
\text { pressure } 151 \mathrm{mmHg} \text { ) }\end{array}$ & $16.5(1.00)$ & $16.0(0.85)$ \\
\hline $\boldsymbol{B}$ & $\begin{array}{l}\text { Ten minutes after induction } \\
\text { of general anaesthesia (systolic } \\
\text { arterial pressure } 113 \mathrm{mmHg} \text { ) }\end{array}$ & $8.4(0.54)$ & $8.4(0.61)$ \\
\hline$C$ & $\begin{array}{l}\text { At end of cataract surgery } \\
\text { (systolic arterial pressure } \\
112 \mathrm{mmHg} \text { ) }\end{array}$ & $7.9(0.54)$ & - \\
\hline$D$ & $\begin{array}{l}\text { After reversal of relaxant drugs, } \\
\text { during spontaneous breathing } \\
\text { (systolic arterial pressure } \\
126 \mathrm{mmHg} \text { ) }\end{array}$ & $12 \cdot 1(0 \cdot 84)$ & - \\
\hline
\end{tabular}


fairly constant thereafter throughout the operation and rose slightly towards the preoperative value when the residual neuromuscular blockage had been reversed with neostigmine and atropine, the nitrous oxide and halothane had been withdrawn, and spontaneous breathing had become re-established on oxygen (Table 1).

\section{ARTERIAL BLOOD GASES}

The mean arterial carbon dioxide tension $\left(\mathrm{PaCO}_{2}\right)$ of blood taken at the end of surgery, while the patient was still being ventilated, was $42.0 \mathrm{mmHg}$ (SE mean, $0.98 \mathrm{mmHg}$ ). The mean arterial oxygen tension $\left(\mathrm{PaO}_{2}\right)$ at this time was $127.6 \mathrm{mmHg}$, the mean arterial $\mathrm{pH}$ was $7 \cdot 374$, and the mean base deficit was $0.8 \mathrm{mmol} /$ litre. Because $\mathrm{pH}$ is a logarithmic function, the mean $\mathrm{pH}$ value stated above was calculated after conversion of the individual $\mathrm{pH}$ values into terms of hydrogen ion concentrations.

POSTOPERATIVE PROBLEMS

There were no systemic complications in any of the patients. One patient had a small iris prolapse which did not require repair. Another patient, who was a diabetic, had a persistent hyphaema and a raised IOP, which resolved satisfactorily.

\section{Discussion}

General anaesthesia has only slowly become accepted as the method of choice in ophthalmic surgery. The eye can easily be rendered insensitive and immobile by local anaesthetics, and as recently as 1966, this was the method of choice proposed for cataract extraction (Snow and Sensel, 1966).

The chief problem of general anaesthesia has been its unpredictable effect on IOP. This question has engaged the attention of anaesthetists for many years without a completely satisfactory solution, as shown by the wealth of papers claiming superiority for various techniques (Ives, 1959; Burn and Knight, 1969; Jones et al., 1969; Smith et al., 1972; Delilkan and Chandran, 1972; Lynch et al., 1974).

All eye surgeons must have experienced at some time the unnerving complications resulting from a raised IOP during intraocular surgery. Such danger signs as a shallow anterior chamber with iris prolapse on opening the eye, caused by an anterior shift of the lens-iris diaphragm, may be followed by vitreous loss, retinal haemorrhage, and choroidal haemorrhage which may be so massive as to take the form of that major disaster, an expulsive haemorrhage (Ruiz and Salmonsen, 1976).

The progress of general anaesthesia in recent years is illustrated by the figures from the Oxford Eye Hospital. In $196557 \%$ of all operations were performed under local anaesthesia; by 1971 the proportion had fallen to $20 \%$. The figures for cataract extraction are even more striking, for, while in $196597 \%$ of these procedures were done under local anaesthesia, in 1971 the figure had fallen to $13.5 \%$. Similarly, of 1133 cataract extractions performed at Moorfields Eye Hospital, London, in $1974-75$ only $4.6 \%$ were performed under local anaesthesia. Many of the mechanisms which cause a change in intracranial pressure have a similar effect on IOP.

The importance of giving a large dose of suxamethonium to facilitate endotracheal intubation has already been mentioned. Contracture of extraocular muscle is not the only effect of suxamethonium, as section of the muscles does not completely abolish the rise in IOP (Craythorne et al., 1960; Adams and Barnett, 1966). Suxamethonium probably increases the blood flow in the choroid, resulting in raised blood volume and increased IOP (Wahlin, 1960; Adams and Barnett, 1966; Wilson et al., 1974). This rise in IOP cannot be prevented entirely by prior administration of small doses of pancuronium (Miller et al., 1958; Bowen et al., 1976). The administration of even a large dose of suxamethonium still poses a problem in patients with penetrating eye injuries, since a rise in IOP may result in a loss of ocular contents. Its administration in these circumstances should be avoided unless doing so would expose the patient to greater hazard. It has been shown that acetazolamide increases choroidal blood flow by up to three times. This drug has previously been claimed to prevent suxamethoniuminduced rise of intraocular pressure, though the mechanism is obscure (Carballo, 1965). It seems likely that acetazolamide may in fact produce an increase in IOP itself, after which the effect of suxamethonium is attenuated (Holloway, 1977). Suxamethonium similarly produces no further pressure rise in eyes in which the tension is already high, and there is therefore no contraindication to its use in glaucoma and related conditions.

Non-depolarising muscle relaxants generally have only a small effect on IOP consequent upon the relaxation of the extraocular muscles and the orbicularis oculi (Duncalf and Foldes, 1973; Eriksen et al., 1977). Tubocurarine may have a greater effect because of its hypotensive activity.

A rise in systemic arterial pressure does not produce a rise in IOP as vessels constrict and blood flow diminishes. A fall in arterial pressure below normal levels does, however, produce a concomitant and progressive fall in IOP. Any drug or technique which produces a fall in arterial pressure will therefore be effective in lowering IOP (Scullica et al., 1973). The ganglion-blocking agents have been 
previously used for this purpose, although few would now consider such use to be indicated for ophthalmic surgery.

The central venous pressure has an important effect on IOP, as any rise interferes with the venous outflow and aqueous drainage from the eye, resulting in a rise of IOP. Hence it is important to prevent coughing, vomiting, and straining.

Arterial carbon dioxide tension has been shown to be a potent determinant of IOP, probably by altering blood flow through the choroid and retrobulbar vessels. IOP varies directly with $\mathrm{CO}_{2}$ tension within a fairly wide range of values.

Intravenous and inhalational anaesthetic agents promote a fall in IOP, which generally increases with increasing depth of anaesthesia. The administration of an adequate dose of thiopentone immediately before giving suxamethonium to some extent reduces the rise in IOP which would otherwise be caused by a first dose of suxamethonium. The action of halothane in lowering IOP is in contrast to its effect on intracranial pressure. Ketamine and trichloroethylene are the exceptions in this group of drugs; their administration is followed by a slight rise in IOP (Yoshikawa and Murai, 1971; Al Abrak and Samuel, 1975). However, claims that ketamine is not associated with any increase in IOP should be viewed with some suspicion, because pretreatment with diazepam (Peuler et al., 1975) or pethidine (Ausinsch et al., 1976) may be responsible.

From the foregoing considerations it is clear that many drugs and techniques permit the intraocular tension to be actively lowered or at least prevented from rising, and a suitably soft eye for intraocular surgery can be produced by a combination of methods.

Most patients requiring cataract extraction are elderly and are therefore likely to suffer from cardiovascular and respiratory dysfunction. With spontaneous respiration during anaesthesia, such patients commonly hypoventilate, with consequent development of hypercapnia, hypoxia, and reduction of functional residual capacity, increasing the risk of postoperative pulmonary collapse and infection. There are also disadvantages in artificial ventilation with the production of hypocapnia: cardiac output is reduced (Prys-Roberts et al., 1967), and depletion of carbon dioxide stores means that postoperative hypoventilation with hypoxaemia is inevitable (Salvatore et al., 1969).

For these reasons a technique for cataract surgery which produces a significant fall in IOP while maintaining a near-normal arterial carbon dioxide tension together with adequate ventilation and oxygenation appears desirable. This is achieved by controlled ventilation with a partial rebreathing circuit such as the Bain circuit. The circuit is particularly appropriate for head and neck surgery as it is light in weight, of a suitable length $(2 \mathrm{~m})$, and has its valve and connections well away from the patient. Anaesthesia with a nitrous oxide and oxygen mixture containing $0.5 \%$ halothane and controlled ventilation following administration of a non-depolarising muscle relaxant, after induction as described above, produced the required operating conditions for intraocular surgery: the mean intraoperative IOP was $52 \%$ of the preanaesthetic level.

This technique has several advantages for intraocular surgery in elderly patients. Muscle relaxation prevents the possibility of straining or coughing during the operation. Oxygenation and adequate lung inflation are ensured by hyperventilation without hypocapnia. The technique ensures a soft eye even when preoperative IOP is high. In many cases an air bubble was spontaneously retained in the anterior chamber when the eye was opened. The return of adequate spontaneous ventilation is achieved promptly after reversal, making it suitable for relatively short ( $\frac{1}{2}$ to $\frac{3}{4}$ hour) cases, and recovery of protective reflexes and consciousness is rapid.

Addendum.-The Beaver ventilator is no longer manufactured. The Cape Minor has proved to be so successful as an inexpensive and simple electrically-powered ventilator for use with the Bain circuit that the manufacturers (Cape Engineering Co., Warwick) now produce a much improved version, the Cape TC50. This new machine permits an infinitely variable frequency of between 10 and 50 cycles/ minute by means of a thyristor-controlled motor (Adams, 1977b). There is an improved preset and directly calibrated tidal volume control, while the important feature of a bellows circuit that can be autoclaved is retained.

\section{References}

Adams, A. K., and Barnett, K. C. (1966). Anaesthesia and intraocular pressure. Anaesthesia, 21, 202-210.

Adams, A. P. (1977a). The Bain circuit. Prevention of anaesthetic mixture dilution when using mechanical ventilators delivering non-anaesthetic gases. Anaesthesia, 32, 46-49.

Adams, A. P. (1977b). Anaesthetic ventilators and associated breathing circuits. British Journal of Clinical Equipment, 1, 133-151.

Adams, A. P., and Fordham, R. M. M. (1973). General anaesthesia in adults. International Ophthalmology Clinics, 13, 83-98.

Al-Abrak, M. H., and Samuel, J. R. (1974). Further observations on the effects of general anaesthesia on intraocular pressure in man: halothane in nitrous oxide and oxygen. British Journal of Anaesthesia, 46, 756-759.

Al-Abrak, M., and Samuel, J. R. (1975). Effects of general anaesthesia on the intraocular pressure in man. Trichloroethylene in nitrous oxide and oxygen. British Journal of Ophthalmology, 59, 107-110.

Ausinsch, B., Rayburn, R. L., Munson, E., and Levy, N. S. (1976). Ketamine and intraocular pressure in children. Anesthesia and Analgesia; Current Researches, 55, 773775.

Bain, J. A., and Spoerel, W. E. (1972). A streamlined anaes- 
thetic system. Canadian Anaesthetists' Society Journal, 19, 426-435.

Bain, J. A., and Spoerel, W. E. (1973). Flow requirements for a modified Mapleson D system during controlled ventilation. Canadian Anaesthetists' Society Journal, 20, 629-636.

Bowen, D. J., McGrand, J. C., and Palmer, R. J. (1976). Intraocular pressures after suxamethonium and endotracheal intubation in patients pre-treated with pancuronium. British Journal of Anaesthesia, 48, 1201-1205.

Burn, R. A., and Knight, P. (1969). Anaesthesia in ophthalmic surgery. British Journal of Hospital Medicine, 2, 1527-1544.

Carballo, A. S. (1965). Succinylcholine and acetazolamide (Diamox) in anaesthesia for ocular surgery. Canadian Anaesthetists' Society Journal, 12, 486-498.

Collis, J. M. (1967). Three simple ventilators. An assessment. Anaesthesia, 22, 598-606.

Conway, C. M., Leigh, J. M., Preston, T. D., Walters, F. J. M., and Webb, D. A. (1974). An assessment of three electronic respirometers. British Journal of Anaesthesia, 46, 885-891.

Craythorne, N. W. B., Rottenstein, H. S., and Dripps, R. D. (1960). Effect of succinylcholine on intraocular pressure in adults, infants and children during general anesthesia. Anesthesiology, 21, 59-63.

Delilkan, A. E., and Chandran, S. (1972). A three-year review of anesthesia for cataract extractions. Anesthesia and Analgesia; Current Researches, 51, 506-508

Duckworth, S. I. (1962). The Oxford non-kinking endotracheal tube: results of its use in about 18000 cases. Anaesthesia, 17, 208-214.

Duncalf, D., and Foldes, F. F. (1973). Effect of anesthetic drugs and muscle relaxants on intraocular pressure. International Ophthalmology Clinics, 13, 21-33.

Eriksen, S., Bramsen, T., and Hommelgaard, P. (1977). Some aspects of ocular function after precurarization. Acta Anaesthesiologica Scandinavica, 21, 385-389.

Gibb, D. B. (1974). Suxamethonium-a review. Pharmacological actions of suxamethonium apart from its neuromuscular blocking effect. Anaesthesia and Intensive Care, 2, 9-26.

Henville, J. D., and Adams, A. P. (1976a). A co-axial breathing circuit and scavenging valve. Anaesthesia, 31, 257-258.

Henville, J. D., and Adams, A. P. (1976b). The Bain anaesthetic system. An assessment during controlled ventilation. Anaesthesia, 31, 247-256.

Holloway, K. B. (1977). Factors affecting intraocular pressure. Proceedings of the Royal Society of Medicine, 70, 144.

Ives, J. (1959). Combined local and general analgesia for cataract operations. British Medical Journal, 1, 821-823.

Jones, W. M., Samis, W. D., Macdonald, D. A., and Boyes, H. W. (1969). Neuroleptanalgesia for intraocular surgery. Canadian Journal of Ophthalmology, 4, 163-168.

Joshi, C., and Bruce, D. L. (1975). Thiopental and succinylcholine: action on intraocular pressure. Anesthesia and Analgesia; Current Researches, 54, 471-475.

Kaufman, L. (1967). General anaesthesia in ophthalmology. Proceedings of the Royal Society of Medicine, 60, 1275-1280.

Kelman, G. R., and Nunn, J. F. (1966). Nomograms for correction of blood $\mathrm{PO}_{2}, \mathrm{PCO}_{2}, \mathrm{pH}$ and base excess for time and temperature. Journal of Applied Physiology, 21, 1484-1490.

Lynch, S., Wolf, G. L., and Berlin, I. (1974). General anesthesia for cataract surgery: a comparative review of
2217 consecutive cases. Anesthesia and Analgesia: Current Researches, 53, 909-913.

Magora, F., and Collins, V. J. (1961). The influence of general anesthesia agents on intraocular pressure in man. Archives of Ophthalmology, 66, 806-811.

Miller, R. D., Way, W. L., and Hickey, R. F. (1968). Inhibition of succinylcholine-induced increased intraocular pressure by non-depolarising muscle relaxants. Anesthesiology, 29, 123-126.

Mushin, W. W., Rendell-Baker, L., Thompson, P. N., and Mapleson, W. W. (1969). Automatic Ventilation of the Lungs, 2nd edn., p. 313-320. Blackwell Scientific Publications: Oxford.

Pandey, K., Badola, R. P., and Kumar, S. (1972). Time course of intraocular hypertension produced by suxamethonium. British Journal of Ophthalmology, 44, 191-196.

Perkins, E. S. (1965). Hand-held applanation tonometer. British Journal of Ophthalmology, 49, 591-593.

Peuler, M., Glass, D. D., and Arens, J. F. (1975). Ketamine and intraocular pressure. Anesthesiology, 43, 575-578.

Prys-Roberts, C., Kelman, G. R., Greenbaum, R., and Robinson, R. H. (1967). Circulatory influences of artificial ventilation during nitrous oxide anaesthesia in man. II: Results: the relative influence of mean intrathoracic pressure and arterial carbon dioxide tension. British Journal of Anaesthesia, 39, 533-548.

Prys-Roberts, C., Meloche, R., and Foëx, P. (1971). Studies of anaesthesia in relation to hypertension. I: Cardiovascular responses of treated and untreated patients. British Journal of Anaesthesia, 43, 122-137.

Ruiz, R. S., and Salmonsen, P. C. (1976). Expulsive choroidal effusion. Archives of Ophthalmology, 94, 69-70.

Salvatore, A. J., Sullivan, S. F., and Papper, E. M. (1969). Postoperative hypoventilation and hypoxaemia after hyperventilation. New England Journal of Medicine, 280, 467-470.

Samuel, J. R., and Beaugié, A. (1974). Effect of carbon dioxide on the intraocular pressure in man during general anaesthesia. British Journal of Ophthalmology, 58, 62-67.

Scullica, L., Montanini, S., Sinardi, A., and De Salvo, R. (1973). Advantages of arterial hypotension in ocular surgery. Bollettino della Societa Italiana di Biologia Sperimentale, 49, 938-944.

Smith, I., Beveridge, M. E., and Wyllie, A. M. (1972). 4-hydroxybutyrate narcosis for ophthalmic surgery. British Journal of Ophthalmology, 56, 429-435.

Snow, J. C., and Sensel, S. (1966). A review of cataract extraction under local and general anesthesia at the Massachusetts Eye and Ear Infirmary. Anesthesia and Analgesia; Current Researches, 45, 742-747.

Taylor, T. H., Mulcahy, M., and Nightingale, D. A. (1968). Suxamethonium chloride in intraocular surgery. British Journal of Anaesthesia, 40, 113-118.

Wahlin, A. (1960). Clinical and experimental studies on effects of succinylcholine. Acta Anaesthesiologica Scandinavica, Supplement, 5, 1-24.

Wilson, T. M., Le May, M., Holloway, K. B., Strang, R., and McKenzie, E. (1974). Experimental and clinical study of factors influencing choroidal blood flow. Transactions of the Ophthalmological Societies of the United Kingdom, 94, 378-382.

Wislicki, L. (1976). Factors affecting intraocular pressure. Proceedings of the Royal Society of Medicine, 69, 952.

Yoshikawa, K., and Murai, Y. (1971). The effect of ketamine on intraocular pressure in children. Anesthesia and Analgesia; Current Researches, 50, 199-202. 